Florida International University FIU Digital Commons

10-11-1991

\title{
The influence of the quality of the sibling bond between sisters on caregiver's burden
}

Mary Etheart

Florida International University

DOI: $10.25148 /$ etd.FI15101320

Follow this and additional works at: https://digitalcommons.fiu.edu/etd

Part of the Psychology Commons

\section{Recommended Citation}

Etheart, Mary, "The influence of the quality of the sibling bond between sisters on caregiver's burden" (1991). FIU Electronic Theses and Dissertations. 3330.

https://digitalcommons.fiu.edu/etd/3330

This work is brought to you for free and open access by the University Graduate School at FIU Digital Commons. It has been accepted for inclusion in FIU Electronic Theses and Dissertations by an authorized administrator of FIU Digital Commons. For more information, please contact dcc@fiu.edu. 


\begin{abstract}
OF THE THESIS
The Influence of the Quality of the sibling Bond

Between Sisters on Caregiver's Burden
\end{abstract}

by

\begin{abstract}
Mary Emerson Etheart
Florida International University, 1991

Miami, Florida

Professor Joan Erber, Major Professor
\end{abstract}

The various stresses experienced by the individual providing care for an elderly spouse or parent are referred to as caregiver's burden. The present study examines the influence of the relationship between sisters on the perceived burden of the caregiving daughter. In addition to the quality of the sibling bond, the effect of proximity is also examined.

The 58 participants completed questionnaires which assessed the amount of caregiving, the perceived burden, and the quality of the relationship with the sister. Correlational analyses indicated a strong negative correlation between burden and closeness $(\underline{p}<.01)$. The results of regression analyses indicated that proximity to the sister was not a significant predictor of burden $(\underline{p}<.25)$, but that closeness to the sister predicted $6 \%$ of the variance in perceived burden $(\underline{p}<.01)$.

The findings of this study illustrate that the quality of the sibling bond between sisters can be an important influence on the perception of caregiver's burden. When sisters have a close relationship, even when they do not live in proximity, the perceived burden of the caregiving daughter can be mediated. 


\title{
FLORIDA INTERNATIONAL UNIVERSITY Miami, Florida
}

\section{The Influence of the Quality of the sibling Bond Between Sisters on Caregiver's Burden}

\begin{abstract}
A thesis submitted in partial satisfaction of the requirements for the degree of Master of science in Psychology
\end{abstract}

by

Mary Emerson Etheart 
To Professors: Joan Erber

$$
\begin{aligned}
& \text { Mary Levitt } \\
& \text { William Kurtines }
\end{aligned}
$$

This thesis, having been approved in respect to form and mechanical execution, is referred to you for judgement upon its substantial merit.

Dean Arthur Herriott

College of Arts and Sciences

The thesis of Mary Emerson Etheart is approved.

Mary Levitt

William Kurtines

Joan Erber, Major Professor

Date of Examination: Oct. 11, 1991

Dean Richard Campbell

Division of Graduate Studies

Florida International University, 1991

(ii) 
Contents

List of Tables . . . . . . . . . . . . . . . iv Introduction . . . . . . . . . . . . . . . . . 1 Background .. . . . . . . . . . . . . . 4

Parental Care by Adult Children . . . . . . . . 4 Burden Research . . . . . . . . . . . . . 9

Sibling Research . . . . . . . . . . . . . 11 Summary \& Hypotheses . . . . . . . . . . . . . 17 Method . . . . . . . . . . . . . . 19 Subjects Materials and Procedure Results . . . . . . . . . . . . . . . 22 Discussion . . . . . . . . . . . . 25 Tables . . . . . . . . . . . . . . 32 References .................. . . 38 Appendices . . . . . . . . . . . . . . . . 44 


\section{List of Tables}

1. Means and standard Deviations of Six Descriptive Variables and Activity, Burden, and closeness as a Function of Proximity . . . . . . . . . 32

2. Pearson-r Correlations . . . . . . . . . . . . 33

3. Model 1: Multiple Regression with Burden as the Dependent Variable . . . . . . . . . . . 34

4. Model 2: Multiple Regression with Burden as the Dependent Variable . . . . . . . . . . . 35

5. Model 3: Multiple Regression with Burden as the Dependent Variable . . . . . . . . . . 36

6. Final Model: Multiple Regression with Burden as the Dependent Variable . . . . . . . . . . . 37 


\section{INTRODUCTION}

In recent years, research interest in sibling relationships has grown rapidly. Moving from a focus on the impact of structure variables (e.g., family size; age spacing) to an emphasis on observation and analysis of the dynamics of sibling interaction, investigators in the field have described this relationship in terms of its quality, endurance, functions, and influence. The sibling relationships studied have focused primarily on siblings in childhood or elderly siblings, thus leaving a void in terms of the middle-age years. Since $78 \%$ of people have a sibling available throughout their adult life (Cicirelli,1985a), it is important to examine that relationship throughout life rather than focusing on the extremes.

certain patterns of sibling interaction have been found by a number of researchers. One significant pattern is that of increased closeness with increased age (Cicirelli, 1977; 1980a,b; Ross, Dalton \& Milgram, 1980; Ross \& Milgram, 1982; Shulman, 1975). There also seems to be a decrease in frequency of contact with increasing age (Rosenberg \& Anspach, 1973) and geographical distance, but pairs of sisters have been found to have the closest relationship across all ages (Adams, 1968; Cicirelli, 1977; Cumming \& Schneider, 1961; Pulakos, 1987; Ross et al, 1982) and distance (Adams, 1968; Connidis, 1988). Connidis (1989) 
suggests that women may be more inclined to maintain contact due to a greater sense of familial obligation.

The activity and endurance of female relationships is also seen in the mother-daughter relationship, especially with increasing age. Recent research has estimated that from $17-30 \%$ of non-institutionalized elderly require some home-care assistance (Stoller, 1983). When a spouse is not present, adult daughters provide this help (Shanas, 1979). The majority of both recipients and providers of care are women due to the larger ratio of women to men over 75 , and it is the middle-generation women who provide the majority of personal care and instrumental services to their widowed mothers (Brody et al., 1983).

It has been established that the provision of care to those who suffer from Alzheimer's or senile dementia frequently results in feelings of burden by that caregiver. Zarit, Reever, \& Peterson (1980) found that the amount of burden felt by caregivers was less when more visits were paid to the patient by other relatives. Studies have not yet examined the perception of burden by caregivers of less severely impaired elderly, nor have they examined the caregiver's relationship to other relatives who may or may not provide support.

It is the purpose of this study to describe how the sibling relationship may affect the perception of burden felt by the middle-aged daughter who provides caregiving 
assistance to her elderly mother. Brody (1981) has termed the middle-aged woman who must cope with the demands and juggle the roles of employment, motherhood, and caregiving daughter as "the woman in the middle". Shanas (1979) has pointed out that family help, exchange of services, and regular visits are common among old people and their children. It is well established that it is daughters who provide the majority of caregiving and instrumental support, but little is known about how sisters share or fail to share this responsibility. Usually, one daughter is the primary caregiver (Brody, 1985). It may be that the quality of her relationship with her sister influences the amount of caregiving burden she feels. An assumption based on research indicating that sisters have the closest relationship among siblings (e.g., Cicirelli, 1977; Ross \& Milgram, 1982) is that sisters also function in supportive roles for one another. However, proximity may confound the issue since frequency of contact diminishes with increasing geographical distance. The supportive role of a sister would be influenced by distance; in proximity, both functional and emotional support could be provided. However, it is possible that when two sisters are geographically distant, their emotional closeness provides support and diminishes the perceived burden of the caregiving member of the dyad. Goetting (1986) has suggested that enhanced closeness may even be a function of 
diminished contact. Since contact is also a function of distance, a plausible assumption could be that sisters who are geographically distant might be more likely to have an emotionally close, thus supportive, relationship. However, if the sisters live in proximity to each other and do not have a close relationship, they would not funtion in supportive roles for each other. The result might be greater perceived burden felt by the caregiving daughter because she does not receive either emotional or functional support from her sister. Her possible resentment of that lack of support could even amplify her perception of caregiving burden.

\section{BACKGROUND}

\section{PARENTAL CARE BY ADULT CHILDREN}

Contrary to what used to be popular belief, the majority of the elderly are not abandoned by their families or institutionalized. Studies from the 1963 symposium sponsored by the Gerontological Society and Duke University (Brody, 1985) produced clear evidence that older people are not alienated from their families, but are in fact taken care of by their adult children when need be. Shanas (1979) found that the majority of sick and frail elderly were not in institutions or group quarters, but were living in their own homes or in the homes of family members. This population of elderly are in need of assistance and Shanas found that, after spouses, children within and outside the 
household were the main source of help. One-third of the elderly women mentioned being taken care of by their children.

Shanas (1979) also examined the visiting patterns of old people and their children and found that more than half of her elderly subjects had seen their children within two days of her interview. Only one subject in ten had not seen a child in over a month. Obviously, then, adult children and their parents remain in relatively close contact throughout the parents' lives. As parents age, and particularly after one has died, the contact with children frequently involves some caregiving on the part of the adult child. In fact, Brody (1985) considers parent care to be a normative, although stressful, experience for individuals and families.

Clark and Rakowski (1983) have categorized caregiving tasks into four broad areas: (a) direct care; (b) intrapersonal tasks, concerns and difficulties; (c) interpersonal ties with other family members; and (d) interaction with broader societal and health care networks. within the first three categories they have identified particular tasks, such as compensation for emotional drain from constant responsibility and balancing the giving of assistance with other family responsibilities, as stressful or particularly difficult. It is interesting to note that within the interpersonal category, anger at other family 
members for not regularly helping is related to these stressful tasks.

Ikels (1983) has conducted research to determine how and why a particular child assumes the responsibility for the well-being of a parent. Although her subjects were of Irish and Chinese ancestry, she identified particular factors involved in the process of caretaker selection which transcend cultural differences. An only child is, of course, the first to be selected as caregiver, followed by an only child of the preferred sex or the only proximate child. Antecedent events which strongly influence the process are the parental age and household composition at the time widowhood occurs. If a child is still living at home when a parent is widowed, that child will be likely to assume caretaking responsibility. However, when all children have left home but one remains in the area, that child has almost no choice but to accept the caretaking role. Ikels terms this the "demographic imperative". When several children of the appropriate sex are fairly equally proximate, other considerations are used in the selection process. The most likely candidate will be the child who owes the parent a special debt (incurred as a result of special assistance provided by the parent such as financial aid or child care), or the sibling with the fewest competing demands. 
Brody (1981) and stoller (1983) have both found that daughters provide the largest proportion of assistance. In her sample of middle-generation women (mean age 49.1) Brody found that $51 \%$ of them provided their mothers with one or more needed services.

stoller's study measured the number of hours of assistance provided by children to the older person during an average month. Time estimates included the time of travel between homes, hours spent assisting with food preparation, shopping, managing personal finances, light and heavy chores, filling out applications and arranging appointments, laundry, and personal care. Her independent variables included the functional characteristics of the parent, availability of spouses, and familial and employment responsibilities. She found that employment significantly decreased the number of hours of assistance provided by sons, but did not have a significant impact on the hours of assistance provided by daughters. No significant correlation was found between the number of young children in the home and the number of hours of assistance provided by either sons or daughters. These findings are in agreement with those of Brody who described the pressures on "the woman in the middle". stoller found that not only did daughters provide a larger number of hours of assistance to parents than did sons, but daughters also showed greater variability in their hours of assistance. Stoller (1983) 
suggests that daughters "may be more responsive to differing levels of need for care or, perhaps, [this finding reflects] a greater variation in the patterns of informal exchanges between daughters and their parents regardless of functional capacity" (p.854).

Given that daughters are expected to and often do assume the responsibility for providing care and assistance to their elderly mothers, it is important to analyze their feelings concerning this role. Archbold (1983) has identified two parent-caring roles: care-provider, who identifies and performs needed services, and care-manager, who identifies needed services and manages their provision by others. She found that both providers and managers experienced difficulties in sibling relationships which they attributed to the role of parent caring. Sibling conflict was created by perceived inequities in the distribution of parent caring activities.

Scharlach (1983, as cited in Remnet, 1987) found that when daughters feel either that they do more than they feel realistically able to do, or that they think they are not doing enough for their mother, the relationship with the mother is affected. The more dissatisfied the daughters feel, the less enjoyment there is in the relationship and the less the mothers will benefit from it.

In summary, the research cited in this section indicates that the elderly are being taken care of either in 
their own homes or within their children's homes, and that daughters are providing most of the needed care and assistance. It is likely that the most proximate daughter fulfills this role, but if sisters are fairly equally proximate there may be sibling conflict generated by perceived inequities of caregiving responsibilities. The mother-daughter relationship may suffer when the daughter feels either that she is being asked to do too much or that she is not doing enough. These feelings may be considered a type of burden, which is the topic of the following section. BURDEN RESEARCH

Caregiver burden refers to "physical, psychological or emotional, social, and financial problems that can be experienced by family members caring for impaired older adults" (George \& Gwyther, 1986, p. 253). Brody (1985) has estimated that over 5 million people are involved in parentcare at any given time and that the most pervasive consequence from this responsibility is emotional strain.

The issues examined in this area include the measurement of caregiver burden (zarit, Reever, \& BachPeterson, 1980), correlates of burden (Poulshock \& Diemling, 1984), and various descriptions and evaluations of programs designed to ease burden. Although most subjects used in this research are involved in caring for parents suffering from Alzheimer's or senile dementia, most studies have not found a correlation between the extent of the patient's 
functional impairment and the feelings of burden experienced by the caregiver. In Poulshock \& Diemling's study (1984) impairment never explained as much as $25 \%$ of the variance in a correlated burden measure. The functional decline of the patient accounted for only $14 \%$ of the variance in caregiver's burden in a study by Novak and Guest (1989) . These researchers found burden best predicted by the caregiver's subjective feelings and needs.

Some researchers have concluded that the amount of caregiver burden depends largely on the context of the caregiving experience (Pett, Caserta, Hutton, \& Lund, 1988). George and Gwyther (1986) found that characteristics of the caregiving situation, specifically the perceptions of the adequacy of social support, were more closely associated with caregiver well-being than the illness characteristics of the patients.

In examining means by which caregivers cope with burden, Johnson and Catalano (1983) found that children most often use a distancing technique as an adaptive mechanism. One method of establishing distance, used by $12 \%$ of their sample, was enlarging the family network to include others in the day to day care. Poulshock and Diemling (1984) have stated that "the concept of burden should be used to refer to the subjective perceptions of caregivers related to the degree of problems experienced in relation to elders' specific impairments" (p. 238). Since the problems 
experienced by each caregiver vary, and the caregiver's feelings of burden have not been shown to be significantly correlated with the patient's level of impairment, the subjective perception of burden varies widely between individuals. Many factors other than the parent's functional impairment are involved, one of the most important of these being the amount and nature of social support.

\section{SIBLING RESEARCH}

Although research on siblings has focused on a great number of issues from the formation of the sibling relationship and its functions to its influence on individuals and the influence of individuals on it, this review of the literature will concentrate on three issues which are particularly relevant to the research proposed subsequently. Research findings to be reported here describe age-related patterns of sibling interaction, the support functions of the sibling relationship, and the particular impact and characteristics of the sister relationship.

As mentioned in the introduction, the frequency of sibling interaction shows a decreasing pattern with increasing age. Rosenberg and Anspach (1973) found that smaller proportions of older than younger adults interact with available siblings. However, it is important to note

the lack of a comparison group of middle-aged subjects. As 
will be discussed later, life phase may be influential. Interaction frequency also decreases as a function of geographical distance (Adams, 1968), which is somewhat agerelated since siblings are unlikely to be geographically separate until maturity. Although interaction decreases, perceived closeness shows the opposite pattern. A number of researchers report a pattern of increased sibling closeness with increased age (Cicirelli, 1977; 1980a, b; Ross, et al, 1980, 1982; Shulman, 1975).

In examining the pattern and function of sibling contact, Allan (1977) described the adult sibling relationship as marked by diffuse and limited involvement and the focus of the relationship as the maintenance of contact. Contact with a sibling can even be maintained through the intermediary relationship with the parents, who provide a source of information about siblings. He found the most influential factor accounting for variation in amount of sibling contact to be their compatibility and liking for each other. Even when siblings lack compatibility, contact is maintained through the network effect of parents and/or other siblings, but when siblings share positive feelings for each other the amount of contact increases. Mostache et al (1983) also found compatibility to be an important feature of the sibling relationship in the early adult years, while reciprocity became the salient feature in later years, especially during times of stress. 
Researchers who have studied the sibling relationship in terms of how it fits into the individual's social support system or social network have focused on the feature of sibling solidarity. Solidarity refers to the social bond and consists of three components: affection, association, and consensus (Suggs \& Kivett, 1987). In studying kinship structure, Cumming and Schneider (1961) see the sibling bond as an exception to the general pattern of shifts in solidarity through time. Although the mother-child bond is the first bond developed, its importance is replaced by the parent-child bond when the individual matures. The sibling bond, on the other hand, is never replaced and increases in importance with age. In their study of individuals aged 5080, Cumming and Schneider found the sibling bond to be reinvoked at the time when their respondents' children left home, which coincided with the time the respondents' parents were most likely to become a problem. The strength of this bond was indicated by the perception of solidarity with siblings being second in importance only to the solidarity parents felt toward their own children. Moreover, once their children became adults, the sibling bond partially replaced even that tie. The authors suggest that the sibling bond in adulthood "acts as a fundamental axis of socio-emotional interaction" (p.501).

Rather than referring to solidarity, Cicirelli (1980a) looks at the dynamics of family interactions and influences 
in terms of a system composed of three subsystems: parentparent, parent-child, and sibling-sibling. As interactions in one subsystem decrease, the influence of another subsystem on the individual increases. He sees this dynamic as explaining the increased influence of the sibling subsystem with age. However, in his study with college-age women he actually found that both the sibling and the mother-daughter subsystems were important to his subjects. With middle-aged women, perhaps changes in the motherdaughter interaction system will have increased influence on the sibling subsystem.

Shulman (1975) has studied life-stage variations in social network structure and found that the nature of close relationships varies with life cycle changes. In this study, subjects were asked to name the six people closest to them, excluding members of their current household. The youngest respondents (aged 18-30) were least likely to name any kin, subjects over 45 were more likely to name a large proportion of kin, and individuals who were widowed, separated, or divorced were most likely to name a majority of kin. Shulman concludes that "at each stage people tend to establish and sustain networks of relationships geared to the needs and concerns of their particular stage of life" (p.820). Certainly an important stage would be that when one's mother begins to decline. Ross et al (1980; 1982) consider critical incidents rather than life-stage 
variations. They have found that critical incidents do influence sibling relationships. The illness or death of a parent tends to bring siblings closer, while a geographical move away has a negative effect.

Some researchers have attempted to identify the origins of sibling closeness and the means by which it is maintained. Bank and Kahn (1982) find that closeness between siblings flourishes when each sibling feels relatively satisfied with the other in the areas of need for contact and intimacy, personal interaction, complementarity of their roles, and their personal values. In the Ross et al (1982) interviews with older people (aged 55-93), their subjects recalled closeness as developing from childhood experiences and being maintained through shared family values. Other essential factors for the maintenance of sibling closeness were shared memories, regular contact, and the provision of certain support functions.

Across all ages, pairs of sisters have been found to have the closest relationship (Adams, 1968; Cicirelli, 1977; Cumming \& Schneider, 1961; Pulakos, 1987; Ross et al, 1982). Using subjects over age 65, Connidis (1989) reported the highest rate of personal contact between sisters, but she did not measure closeness. In looking at the relationship between contact and distance, Adams (1968) and Connidis (1988) both reported that sisters are the only siblings to overcome distance through communication. However, the 
quality of that communication is marked by a decrease in the mutuality of confiding and discussing important matters.

Cicirelli's (1977) study with elderly subjects (mean age 75.9) indicated that female siblings have a differential effect on men and women. The relationship of elderly women to their sisters appeared to be associated with stimulation and challenge to maintain social activities and roles. Perhaps related to this challenge, Bedford (1989b) found more conflict in women's stories about sisters than in men's stories about brothers. She used a special version of the Thematic Apperception Test to identify the subjects' underlying feelings toward their siblings, and found that women's awareness of those feelings toward sisters was lifephase specific (1989a). Women in the child-rearing phase were more conscious of positive feelings, while women in the empty nest phase were more aware of negative feelings. Bedford suggests that these findings indicate acceptance of feelings which are in tune with the predominant personality characteristics of specific life-periods. Thus, childrearing women are more accepting of the loving and nurturant aspects of the relationship, while empty-nest women would be more willing to accept the aggressive and competitive aspects.

In looking at older women (over 65), Gold (1989) found that the quality of the sibling relationship improves in old age; sisters become more accepting and approving of one 
another, more psychologically involved, and less resentful and envious. Cicirelli (1989) also used elderly subjects (aged 61-91) and found that the perception of closeness to sisters by either men or women was important to the wellbeing of the older person. For women with sisters, closeness was negatively correlated with depression, and conflict and indifference in relationships with sisters were associated with greater depression.

In summary, research has indicated that siblings' closeness to each other increases with age and that life stage (or phase) may be an important factor in the influence and importance of the sibling bond. It seems to be especially important in times of stress, when reciprocity may also become an expected function of the sibling bond. The sister bond has been shown to be the closest, with the relationship between sisters unique and highly influential.

\section{SUMMARY and HYPOTHESES}

Research in the area of parent-care has clearly shown that the elderly are usually taken care of by either their spouse or adult children. When a spouse is not available, it is most often the adult daughter who fulfills the role of caregiver. Since the life expectancy of women is greater than that of men, women are more often widowed than men (Botwinick, 1984). Thus, the people involved in this situation are most often elderly women and their adult daughters. 
Studies on the topic of caregiver burden have demonstrated the stresses involved in parent-care and explored means to lessen the burden. One important finding is that burden is influenced more by social support than by the actual functional impairment of the parent.

Research which has focused on siblings has shown that siblings are often part of a person's social support network. It has been demonstrated that sisters have the closest sibling bond, and that their influence upon each other may be life-stage specific.

This study attempts to combine the research areas of siblings and caregiver burden. The influence of the sibling bond on the perceived burden of middle-aged women is evaluated. The research question is: Does the quality of the sibling relationship affect caregiver burden? The primary hypothesis is that caregiver burden will be lower for women who have a close relationship with their sisters. It is expected that the support provided within an emotionally close relationship will result in the perception of less burden by the caregiving sister. A secondary hypothesis is that physical proximity will interact with emotional closeness to affect perceived burden. Specifically, it is hypothesized that sisters who do not have an emotionally close relationship may perceive the greatest burden when they live in proximity to each other. The underlying assumption is that the caregiver's perceived 
burden may be amplified by the physical proximity of a sister who provides no functional nor emotional support. The converse is also expected; the caregiver's perceived burden may be lessened by the physical proximity of a sister who functions in a supportive role. Thus, the greatest burden will be perceived by sisters close in proximity but who are not emotionally close, and the least burden will be perceived by sisters who are both physically and emotionally close. Between these two extremes, it is expected that sisters who are emotionally close but not physically proximate will perceive less burden than those who are neither physically nor emotionally close.

\section{METHOD}

\section{SUBJECTS}

The 58 women participants (each paid $\$ 5.00$ for participation) were recruited from the community via newspaper ads and fliers posted in public libraries, women's health centers, and other community organizations. Some women were also contacted through day care centers where their mothers spent time and through support groups for caregivers. In order to participate in this study, women had to have only one sister and their mothers were to be over age 65 and living within a $40 \mathrm{mile}$ radius. The mean age of the women was 46.4 years; the range was 30 to 68 years. Seventy-seven percent of the participants were married, $16 \%$ divorced, and $7 \%$ never married. Twenty-five of 
the subjects had a sister who lived near (within 80 miles) and 33 women had a sister who lived far (further than 180 miles). The mean age of the sisters was 47.2 years, with a range of 35 to 68 years. The mean number of children of the participants was 1.7 , although $40 \%$ had no children living at home. Sixty percent of all participants had no brothers; for those 23 subjects who did have brothers, $65 \%$ of those brothers lived nearby.

The majority (60\%) of the participants' mothers lived in their own homes, apartments, or condominiums. of the other mothers, 12 lived with the participant, 7 lived in an adult congregate living facility or retirement home, and 4 lived in nursing homes.

\section{MATERIALS and PROCEDURE}

Each subject was given a series of four questionnaires which they received in the mail along with a stamped return envelope. Seventy-five surveys were mailed, and 60 were returned. Two of the returned surveys were not used due to missing information.

The first questionnaire (see Appendix A) includes demographic data and a measure of perceived closeness to the sister. Closeness is measured on a Likert scale ranging from 1 (not at all close) to 7 (very close).

An activities checklist was given to measure the number and frequency of caregiving activities provided by the subject to her mother (see Appendix B). The 18 items on 
this checklist include instrumental and supportive activities ranging from simple telephoning to assistance with personal care. This checklist was devised by the experimenter based on activities used in interviews of other researchers (Stoller, 1983; Walker \& Thompson, 1983). The frequency of performance of each activity is measured on a 7-point Likert scale anchored by "never" (1) and "daily" (7) .

The Burden Interview was designed by zarit and zarit (1983) to assess the stresses experienced by caregivers of dementia patients. Zarit and zarit report that internal reliability of the Burden Interview has been estimated using Cronbach's alpha at .88 and .91 and test-retest reliability has been reported at .71. They have estimated validity by correlating the total score with a single global rating of burden $(r=.71)$. The Burden Interview consists of 22 questions assessing the caregiver's feelings with respect to the caretaking role (see Appendix c). For each item, the caregiver rates how often she has felt that way on a scale of 0 (never) to 4 (nearly always). Thus, the higher the total score, the greater the perceived burden. In the present study the Burden Interview was used to measure the stresses of caregivers of less impaired elderly.
A fourth questionnaire (see Appendix
D) is a more detailed assessment of the caregiver's closeness to her sister. This survey is adapted from an instrument used by 
Levitt, Coffman and Guacci (1990) to measure perceived closeness. It is composed of twenty statements about the participant's relationship with her sister. The subject indicates the extent to which she agrees with each statement on a scale of 1 (strongly agree) to 5 (strongly disagree). Half of the statements are reverse-scored, and a high total score indicates a close relationship.

The participants also rated their perception of their mother's health using a 7-point Likert scale anchored by "ill health" (1) and "excellent health" (7). Finally, their perception of the extent of their sister's contribution to their mother's care was measured using a 7-point Likert scale anchored by "not at all" (1) and "greatly" (7).

\section{RESULTS}

A one-way multivariate analysis of variance (MANOVA) was performed using proximity as the independent variable. The purpose of this analysis was to ensure the equivalence of the two groups (near vs. far) in terms of descriptive variables such as age, number of children, number of brothers, and sister's age. It was also used to examine the data for differences between the two groups in terms of number of activities, burden, and closeness. Since the two measures of closeness were highly correlated $(\underline{r}(58)=0.77$, $\underline{p}<.01$ ), only the scores from the more detailed assessment (see Appendix D) were used. The MANOVA revealed that there 
was no significant overall effect of proximity, $F(11,46)=$ 1.66, $\mathrm{p}<.1128$. (See Table 1 for the means and standard deviations.)

Although the overall MANOVA was not significant, since it appeared to marginally approach significance the univariates were examined. The only significant univariate was closeness, $F(1,56)=4.33, \mathrm{p}<.04$. Sisters who do not live in geographic proximity appear to have a closer relationship than sisters living near one another $(\mathrm{Ms}=3.98$ and 3.47 for far and near, respectively).

Pearson- $\underline{\underline{r}}$ correlations between all variables were computed. (See Table 2) As expected, a strong positive correlation existed between burden and activities, $\underline{r}(58)=$ $.57, \underline{p}<.01$. A strong negative correlation was found between burden and closeness, $\underline{r}(58)=-.35, \underline{p}<.01$, indicating that the relationship between caregiver's burden and emotional closeness to the sister is in the hypothesized direction. A significant correlation also existed between burden and perception of mother's health, $\underline{r}(58)=-.37, \underline{p}<.01$.

In order to examine how well caregiver burden would be predicted by the different variables, a series of multiple regressions was conducted. In the first equation (Model 1), the predictor variables used were activities, closeness, sister's help, perception of mother's health, and proximity. A sixth variable representing interaction between proximity and closeness was added to the equation. This variable was 
not significant $\left(\underline{p}<.864\right.$; contribution to $\left.\mathrm{R}^{2}=.0003\right)$, indicating homogeneity of slopes for proximity and closeness. The adjusted $R^{2}$ for this model was $.4254, F$ ( 6 , $51)=8.03, \mathrm{p}<.0001$. (See Table 3 for the beta weights, significance levels, and contribution to $R^{2}$ for these variables.) Thus, the sixth variable was deleted from the equation and the aforementioned five predictors were used in Model 2. The result of this analysis indicated that sister's help was not a significant predictor of burden (contribution to $\mathrm{R}^{2}=.01, \mathrm{p}<.32$ ). (See Table 4 for the beta weights, significance levels, and contribution to $\mathrm{R}^{2}$ for these variables.) The adjusted $R^{2}$ for this model was $.4361, \mathrm{~F}(5,52)=9.82, \underline{\mathrm{p}}<.0001$. Since sister's help explained so little of the variance in caregiver's burden, it was removed from the regression model and the predictors used in the next equation (Model 3) were activities, closeness, perception of mother's health, and proximity.

Although it was hypothesized that proximity to the sister would be a significant predictor of caregiver's burden, the results of the regression analysis indicated that it was not. Proximity contributed only .01 ( $<<.25)$ to the $\mathrm{R}^{2}$ of .475 , so it was removed from the model. The adjusted $R^{2}$ for this model was $.4359, F(4,53)=12.02, p<$ .0001 . (See Table 5 for the beta weights, significance levels, and contribution to $\mathrm{R}^{2}$ for these variables.) 
Thus, the predictors in the final model (Model 4) were activities, closeness, and perception of mother's health. These variables contributed significantly to the variance in caregiver's burden, adjusted $\mathrm{R}^{2}=.4323, \mathrm{~F}(3,54)=15.47$, $\mathrm{p}<.0001$. (See Table 6 for the beta weights, significance levels, and contribution to $\mathrm{R}^{2}$ for these variables.) of these variables, activities was the best predictor, explaining $19 \%$ of the variance in burden, while perception of mother's health explained $8 \%$ and closeness to the sister explained $6 \%$

As a direct test of the hypothesis that physical proximity interacts with emotional closeness to affect perceived burden, an $\mathrm{R}$ to $\mathrm{Z}$ transformation was performed on the correlations between closeness and burden for each of the two groups (near, $r=-0.459$; far, $r=-0.327$ ). This analysis indicated no significant difference in the correlations between closeness and burden for the near group and the far group.

\section{DISCUSSION}

Previous research has examined the areas of caregiver's burden and sibling relationships separately. This study combined the two areas to investigate the relationship between caregiver's burden and the sibling bond. Specifically, only sisters were included since daughters are most often the primary caregivers. The primary hypothesis was that caregiving burden would be less for women who have 
a close relationship with their sister. There was a significant negative correlation between perceived burden and closeness, indicating that high closeness with a sister is related to low burden. Thus, the hypothesized relationship between the variables of closeness and burden was illustrated. Although correlational research does not allow cause and effect assumptions, this finding illustrates the relevance of the sibling bond as an important aspect of social support, and suggests that poor sibling relationships and the perception of burden are related. Since it has been established that sisters typically have the closest relationship (Adams, 1968; Cicirelli, 1977; Cumming \& Schneider, 1961; Pulakos, 1987; Ross et al, 1982), it may be that sisters who do not share such a relationship are especially affected in terms of stress and burden.

It is not surprising that burden was best predicted by activities. There was also a significant correlation between burden and activities, indicating that as the number of caregiving activities increases, the perceived burden also increases.

The second best predictor of perceived burden was perception of mother's health, which was an unexpected finding. Other researchers (Poulshock \& Diemling, 1984; Novak \& Guest, 1989) have found no significant correlation between the functional impairment of the parent and the perceived burden of the caregiver. However, there are 
several important differences between the present study and the previous research. The parents in the other studies were usually suffering from Alzheimer's disease, and the researchers measured their actual functional impairment. The mothers of the participants in the present study were, in general, less severely impaired, but also varied a great deal. This variation could lessen the restriction of range that might have existed in other studies.

In this study a measure of the mother's actual functional impairment was not available. The only measure of the mother's health was the daughter's perception. Despite the lack of any objective measure of the mother's impairment, the significant correlation between the daughter's perception of her mother's health and her perceived burden indicates the importance of the caregiver's perceptions. In support of this notion, Novak and Guest (1989) also found that burden was best predicted by the caregiver's subjective feelings and needs. These findings suggest the importance of the caregiver's perceptions of the care recipient's health and needs. In providing support for caregivers, working with their perceptions might be an effective addition to the provision of functional types of assistance.

While activities and perception of mother's health were the two best predictors, closeness to the sister also explained some of the variance in perceived burden. As 
previously mentioned, there was a significant negative correlation between closeness and burden which supports the primary hypothesis of this study. An emotionally close relationship between sisters is related to less perceived burden, while more burden is perceived by caregivers who do not have such a relationship with their sisters. This finding supports the assumption that sisters who have a close relationship function in supportive roles for one another.

A second hypothesis was that closeness and proximity to the sister would interact with regard to burden. It was hypothesized that a close relationship to the sister might lessen perceived burden even when the sister lived too far away to be of any functional assistance. This was proposed because of the underlying assumption that sisters in a close relationship function in supportive roles, and it may be that the provision of emotional support is sufficient to ease the caregiver's perception of burden. It was also hypothesized that a relationship lacking in closeness between sisters who lived near one another might increase the perceived burden of the caregiver. This was expected because of the possible resentment felt by the caregiver whose sister lives near enough to be of assistance yet provides none. It was assumed that without a close relationship to provide emotional support, the proximity of a sister would amplify the caregiver's perception of burden. 
The findings of this study do not support this hypothesis; there was no significant interaction between closeness and proximity and the proximity of the sister did not predict the perceived burden of the caregiver. Also, since proximity did not predict burden, expectations for support from the sister seem to be a function of the emotional relationship more than the geographic proximity. Mostache et al (1983) found reciprocity to be the most salient feature of the sibling relationship in later years, and this reciprocity may be instrumental or expressive. The findings of the present study indicate that there may be supportive reciprocity between sisters who have a close relationship, and that this reciprocity can function regardless of proximity.

The caregiver's perception of her sister's help was not a significant predictor of burden either. However, this study assessed only perceptions of sister's help, which may not be congruent with the actual amount and nature of social support available to the caregivers. It is certainly possible that other types of support might have been available. Also, although the perception of sister's help did not predict burden, it was positively correlated with closeness. This provides further support for the notion that perception of support is a function of the emotional relationship. 
The closest relationship was found between sisters who did not live near one another. This supports Goetting (1986) who suggested that enhanced closeness may actually be a function of diminished contact. Perhaps when sisters are not geographically proximate the chances for conflict, including that over caregiving responsibilities, are reduced and the opportunity for a close relationship with one another is more available.

In summary, this study focused on the influence of the sibling bond between middle-aged sisters, one of whom was providing some caregiving to their mother. The hypotheses were that closeness would be an important influence on the perception of caregiving burden, and that proximity would interact with closeness to influence the perception of burden. The primary finding was that the caregiving sister's perception of burden was lower if she had a close relationship with her sister. The perception of the sister's functional assistance did not appear influential, nor did the sister's geographic proximity. In fact, the closest relationship was found between sisters who did not live near each other. Further research might examine what factors are involved in the relationship between sisters which may enhance closeness even with distance. It would also be helpful to examine the relationship between the mother and her caregiving daughter. Perhaps sisters who 
have a close relationship with each other also have a close relationship with their mother, and this close motherdaughter relationship could account for a lesser sense of perceived burden.

The present findings illustrate the importance of the female sibling relationship during the middle-aged years, a time of life when caregiving responsibilities for a parent often begin. An important influence on the potential caregiving burden is an emotionally close relationship with a sister. Although further research should investigate the influence of other relationships (e.g., those with a spouse, child, or opposite-sex sibling) it is important to recognize the importance of the relationship a caregiving daughter has with her sister. 
Table 1

Means and Standard Deviations of Six Descriptive Variables and Activity, Burden, and closeness as a Function of Proximity

$\begin{array}{ll}\text { Near } & \text { Far } \\ \mathrm{N}=25 & \mathrm{~N}=33\end{array}$

\begin{tabular}{|c|c|c|c|c|}
\hline & Mean & $S D$ & Mean & $S D$ \\
\hline Age & 45.48 & 8.58 & 47.15 & 8.91 \\
\hline $\begin{array}{r}\text { Mother's } \\
\text { Health }\end{array}$ & 4.20 & 2.08 & 4.12 & 1.76 \\
\hline $\begin{array}{c}\text { Sister's } \\
\text { Help }\end{array}$ & 3.84 & 1.99 & 3.03 & 2.06 \\
\hline Sister's Age & 46.84 & 7.85 & 47.57 & 7.11 \\
\hline Children & 1.72 & 1.13 & 1.75 & 1.14 \\
\hline Brothers & 0.40 & 0.57 & 0.78 & 1.11 \\
\hline Activities & 3.20 & 1.22 & 3.32 & 1.48 \\
\hline Burden & 1.16 & .76 & 1.26 & .80 \\
\hline Closeness & 3.47 & .98 & 3.98 & .89 \\
\hline
\end{tabular}


Table 2

Pearson-r Correlations

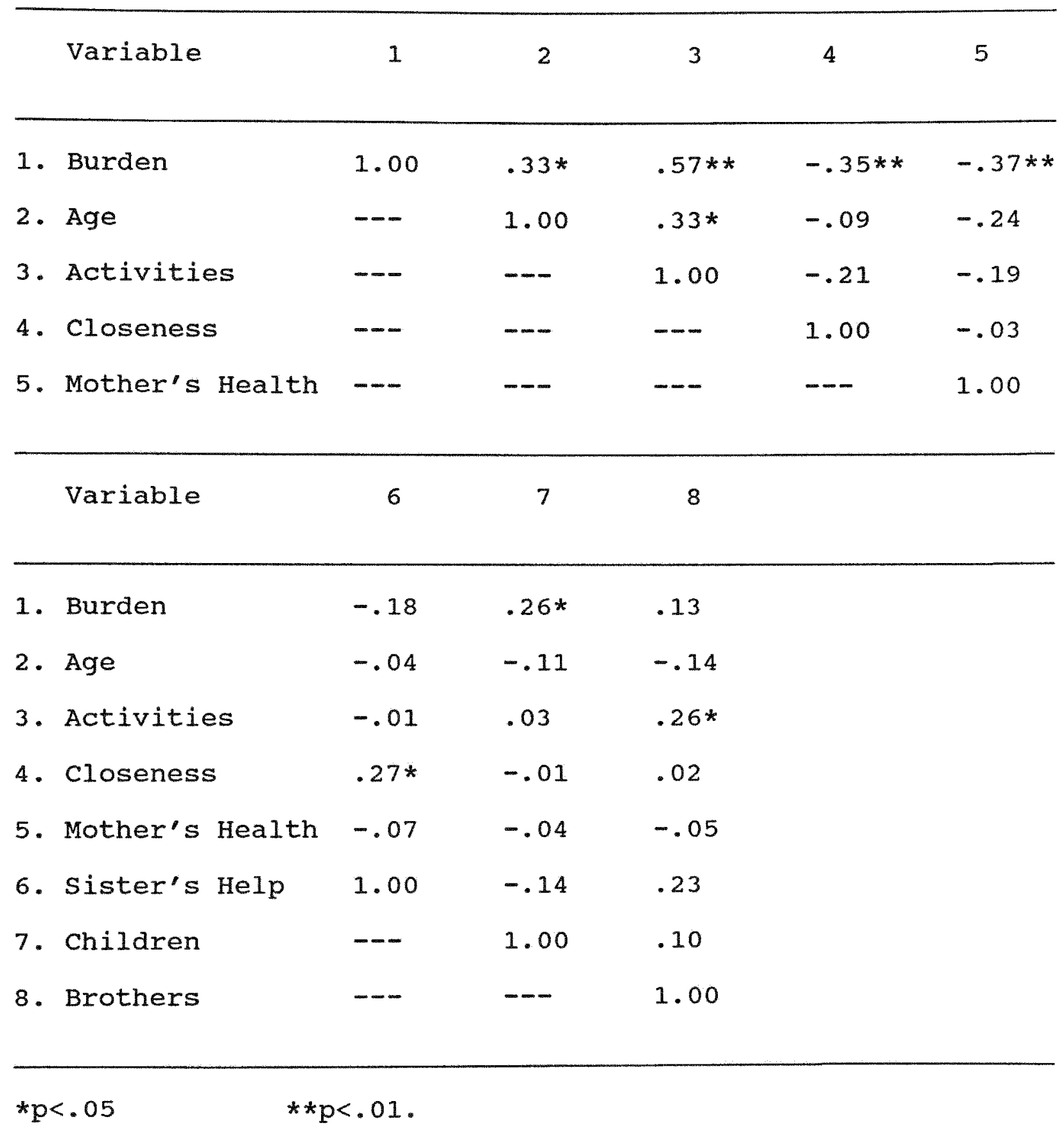


Table 3

Model 1: Multiple Regression with Burden as the Dependent Variable

\begin{tabular}{lcccc}
\hline $\begin{array}{c}\text { Predictor } \\
\text { Variable }\end{array}$ & $\begin{array}{c}\text { Beta } \\
\text { Weight }\end{array}$ & $t$ & $\mathrm{p}$ & $\begin{array}{c}\text { Contribution } \\
\text { to } \mathrm{R}^{2}\end{array}$ \\
\hline Activities & 0.452 & 4.28 & $.000 *$ & .1844 \\
Closeness & -0.241 & -1.50 & .140 & .0227 \\
Sister's Help & -0.110 & -1.01 & .319 & .0102 \\
Mother's Health & -0.301 & -2.91 & $.005 *$ & .0852 \\
Proximity & 0.158 & 0.38 & .709 & .0014 \\
Proxclos & -0.080 & -0.17 & .864 & .0003
\end{tabular}


Table 4

Model 2 : Multiple Regression with Burden as the Dependent Variable

\begin{tabular}{lcccc}
\hline $\begin{array}{c}\text { Predictor } \\
\text { Variable }\end{array}$ & $\begin{array}{c}\text { Beta } \\
\text { Weight }\end{array}$ & $t$ & $\mathrm{p}$ & $\begin{array}{c}\text { Contribution } \\
\text { to } \mathrm{R}^{2}\end{array}$ \\
\hline Activities & 0.452 & 4.32 & $.000 *$ & .1843 \\
Closeness & -0.260 & -2.30 & $.026 *$ & .0521 \\
Sister's Help & -0.109 & -1.01 & .318 & .0100 \\
Mother's Health & -.299 & -2.94 & $.005 *$ & .0853 \\
Proximity & .088 & 0.81 & .421 & .0065
\end{tabular}


Table 5

Model 3 : Multiple Regression with Burden as the Dependent Variable

\begin{tabular}{lcccc}
\hline $\begin{array}{c}\text { Predictor } \\
\text { Variable }\end{array}$ & $\begin{array}{c}\text { Beta } \\
\text { Weight }\end{array}$ & $t$ & $\mathrm{p}$ & $\begin{array}{c}\text { Contribution } \\
\text { to } \mathrm{R}^{2}\end{array}$ \\
\hline Activities & 0.444 & 4.25 & $.000 *$ & .1791 \\
Closeness & -0.299 & -2.82 & $.007 *$ & .0786 \\
Mother's Health & -0.293 & -2.88 & $.006 *$ & .0823 \\
Proximity & 0.121 & 1.16 & .250 & .0133
\end{tabular}


Table 6

Final Model: Multiple Regression with Burden as the Dependent Variable

\begin{tabular}{lcccc}
\hline $\begin{array}{c}\text { Predictor } \\
\text { Variable }\end{array}$ & $\begin{array}{c}\text { Beta } \\
\text { Weight }\end{array}$ & $t$ & $\mathrm{p}$ & $\begin{array}{c}\text { Contribution } \\
\text { to } \mathrm{R}^{2}\end{array}$ \\
\hline Activities & 0.457 & 4.39 & $.000 *$ & .1915 \\
Closeness & -0.265 & -2.59 & $.012 *$ & .0666 \\
Mother's Health & -0.292 & -2.87 & $.006 *$ & .0818
\end{tabular}


Adams, B. (1968). Kinship in an Urban Setting.

Chicago: Markham.

Archbold, P.G. (1983). Impact of parent-caring on women. Family Relations, 32, 39-45.

Allan, G. (1977). Sibling solidarity. Journal of Marriage and the Family, Feb., 177-183.

Bank, S. \& Kahn, M. (1982). The Sibling Bond. New York: Basic.

Bedford, V. (1989a). Ambivalence in adult sibling relationships. Journal of Family Issues, $10,2,211-224$. Bedford, V. (1989b). A comparison of thematic apperceptions of sibling affiliation, conflict, \& separation at two periods of adulthood. International Journal of Aging and Human Development, 28, 1, 53-66.

Botwinick, J. (1984). Aging and Behavior. (3rd ed.)

New York: Springer.

Brody, E. (1981). "Women in the middle" \& family help to older people. The Gerontologist, $21,5,471-479$.

Brody, E. (1985). Parent care as a normative family stress. The Gerontologist, 25, 1, 19-29.

Brody, E., Johnsen, P., Fulcomer, M., \& Lang, A. (1983). Women's changing roles \& help to elderly parents: attitudes of three generations of women. Journal of Gerontology, $38,5,597-607$. 
Cicirelli, V. (1989). Feelings of attachment to siblings and well-being in later life. Psychology \& Aging, 4, 2, 211216 .

Cicirelli, V. (1985a). The role of siblings as family caregivers. In W. Sauer \& R. Coward (Eds.), Social Support Networks and the Care of the Elderly (pp. 93120). New York: Springer.

Cicirelli, V. (1985b). Sibling relationships throughout the lifecycle. In L. L'Abate (Ed.), The Handbook of Family Psychology \& Therapy, Vol. 1, (pp.177-214). Homewood, I11.: Dorsey.

Cicirelli, V. (1982). Sibling influence throughout the lifespan. In M. Lamb \& B. Sutton-Smith (Eds.), sibling Relationships: Their nature and significance across the Iifespan (pp. 267-284). Hillsdale, NJ: Lawrence Erlbaum Ass.

Cicirelli, V. (1980a). A comparison of college women's feelings toward their siblings \& parents. Journal of Marriage \& the Family, Feb., 111-118. Cicirelli, V. (1980b). The relationship of family background variables to locus of control in the elderly. Journal of Gerontology, 35, 108-114.

Cicirelli, v. (1977). Relationship of siblings to the elderly person's feelings \& concerns. Journal of Gerontology, 32 , $317-322$. 
Clark, N. \& Rakowski, W. (1983). Family caregivers of older adults: improving helping skills. The Gerontologist, 23 , $6,637-642$.

Connidis, I. (1989). Siblings as friends in later life. American Behavioral Scientist, 33, 1, 81-93.

Connidis, I. (1988, November). Sibling ties and Aging. Paper presented at the annual meeting of the Gerontological Society of America. San Francisco, CA.

Cumming, E. \& Schneider, D. (1961). Sibling solidarity in American kinship. American Anthropologist, 63, 498-507. Erickson, E. (1963). Childhood and Society. New York: W.W. Norton.

George, L. \& Gwyther, L. (1986). Caregiver well-being: a multidimensional examination of family caregivers of demented adults. The Gerontologist, 26, 3, 253-259. Goetting, A. (1986). The developmental tasks of siblingship over the lifecycle. Journal of Marriage \& the Family, 48, $703-714$.

Gold, D. (1989). Generational solidarity: conceptual antecedents and consequences. American Behavioral Scientist, $33,1,19-32$.

Ikels, C. (1983). The process of caretaker selection. Research on Aging, 5, 4, 491-509.

Johnson, C.L. \& Catalano, D.J. (1983). A longitudinal study of family supports to impaired elderly. The Gerontologist, $23,6,612-618$. 
Levitt, M.J., Coffman, S. \& Guacci, N. (1990, April). Close relationships, maternal well-being, and infant difficulty: An expectancy model. Paper presented at the meeting of the society of Research in Child Development, Seattle, WA.

Mosatche, H., Brady, E., \& Noberini, M. (1983). A

retrospective lifespan study of the closest sibling relationship. Journal of Psychology, 113, 237-243.

Novak, M. \& Guest, C. (1989). Caregiver response to

Alzheimer's disease. International Journal of Aging and Human Development, 28, 1, 67-79.

Pett, M., Caserta, M., Hutton, A., \& Lund, D. (1988).

Intergenerational conflict: middle-aged women caring for demented older adults. American Journal of

Orthopsychiatry, 58, 3, 405-417.

Poulshock, S.W. \& Diemling, G. (1984). Families caring for elders in residence: issues in the measurement of burden. Journal of Gerontology, 39, 2, 230-239.

Pulakos, J. (1987). Brothers \& sisters: nature \& importance of the adult bond. Journal of Psychology, 121, 521-522. Pulakos, J. (1985). Young adult relationships: siblings \& friends. Journal of Psychology, 123, 237-244. Remnet, V. (1987). How adult children respond to role transitions in the lives of their aging parents. Educational Gerontology, 13, 341-355. 
Rosenberg, G. \& Anspach, D. (1973). Sibling solidarity in the working class. Journal of Marriage \& the Family, Feb., 108-113.

Ross, H., Dalton, M.J., \& Milgram, J. (1980 Nov.) older adults' perceptions of closeness in sibling relationships. Paper presented at the 33 rd Annual Scientific Meeting of the Gerontological Society, san Diego:CA. (ERIC Document Reproduction Service No. ED 201 903).

Ross, H. \& Milgram, J. (1982). Important variables in adult sibling relationships: a qualitative study. In M. Lamb \& B. Sutton-Smith (Eds.), Sibling Relationships: Their nature and significance across the lifespan (pp. 225249). Hillsdale, NJ: Erlbaum Ass.

Shanas, E. (1979). The family as a social support system in old age. The Gerontologist, 19, 2, 169-174. Shulman, N. (1975). Life cycle variations in patterns of close relationships. Journal of Marriage \& the Family, Nov., $813-821$

Stoller, E. (1983). Parental caregiving by adult children. Journal of Marriage and the Family, 45, 4, 851-858. Suggs, P. \& Kivett, V. (1987). Rural/urban elderly and siblings: their value consensus. International Journal of Aging \& Human Development, 24, 149-159. 
Walker, A. \& Thompson, I. (1983). Intimacy \& intergenerational aid and contact among mothers \& daughters. Journal of Marriage \& the Family, 45, 841-849.

Zarit, S., Reever, K., \& Bach-Peterson, J. (1980). Relatives of the impaired elderly \& correlates of feelings of burden. The Gerontologist, 20, 6, 649-655.

Zarit, S. \& Zarit, J. (1983). The Burden Interview. Penn State: Authors. 
APPENDIX A 


\section{QUESTIONNAIRE \#1}

1. Date of birth:

2. Marital status (circle one): single married separated

3. Number of children information for each child:

age $\overline{\text { sex }}$ sently living with you?

age sex

currently living with you?

age
currently living with you?

age
currently
siving with you?
Please provide the following

yes no

yes no

yes no

yes no

4. Number of brothers

Number of brothers living within 40 miles of you

5. Please provide the following information about your sister: age marital status (circle one): single married separated my sister lives (circle one): within 40 miles between 40 - 80 miles between 80 - 180 miles further than 180 miles

How close do you feel toward your sister?

3

4

5

6

7

not at all close

very close 
APPENDIX B 


\section{ACTIVITIES CHECKLIST}

INSTRUCTIONS: The following is a list of possible activities some people engage in with or for their mothers. Please use the frequency scale below to indicate how often you perform or participate in each activity for or with your mother.

Frequency scale:

$$
\begin{aligned}
& 1=\text { never } \\
& 2=\text { several times a year } \\
& 3=\text { once a month } \\
& 4=\text { several times a month } \\
& 5=\text { once a week } \\
& 6=\text { several times a week } \\
& 7=\text { daily }
\end{aligned}
$$

\begin{tabular}{|c|c|c|c|c|c|}
\hline $\begin{array}{c}1 \\
\text { never }\end{array}$ & 2 & 3 & 4 & 5 & 6 \\
\hline
\end{tabular}

1. Telephone her

2. Drop in to see her

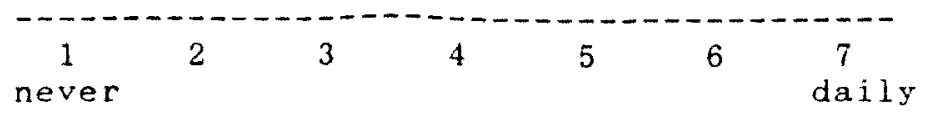

3. Take her grocery shopping

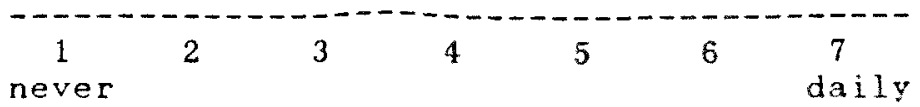

4. Take her shopping for gifts, clothing, household items, etc.

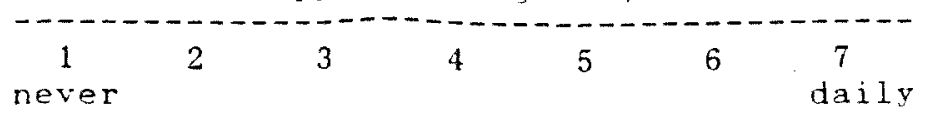

5. Prepare meals for her

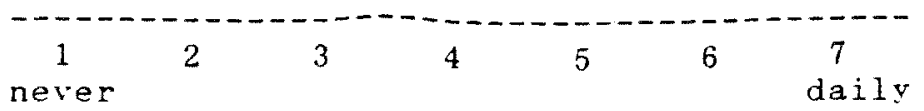

6. Assist her in personal care such as bathing, grooming, dressing

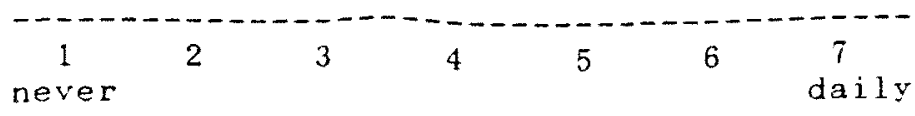

7. Assist her with decision making

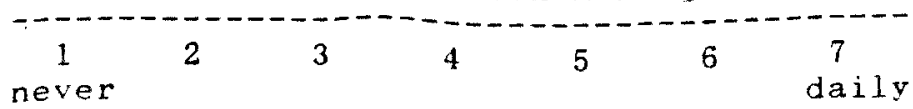


8. Help her with light housekeeping chores like dishes, dusting, laundry

\begin{tabular}{|c|c|c|c|c|c|}
\hline $\begin{array}{c}1 \\
\text { never }\end{array}$ & 2 & 3 & 4 & 5 & 6 \\
\hline
\end{tabular}

9. Help her with heavy housekeeping chores like vacuuming, cleaning floors or windows, etc.

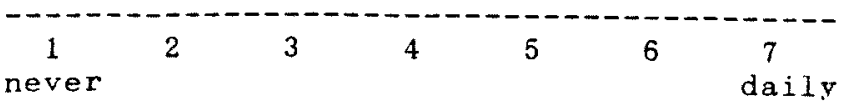

10. Make minor household repairs for her like changing lightbulbs or fuses

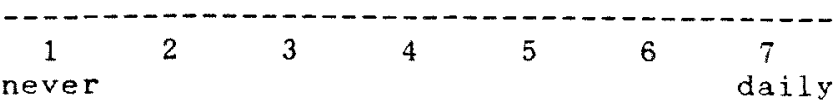

11. Assist her when she's ill in ways such as getting medication for her, supervising the taking of medication, preparing neals

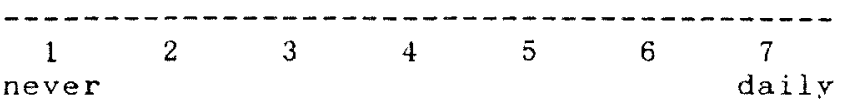

12. Arrange appointments for her with the doctor, dentist, hairdresser, etc.

\begin{tabular}{|c|c|c|c|c|c|}
\hline $\begin{array}{c}1 \\
\text { never }\end{array}$ & 2 & 3 & 4 & 5 & 6 \\
\hline
\end{tabular}

13. Transport or arrange transportation for her to appointments, social activities, etc.

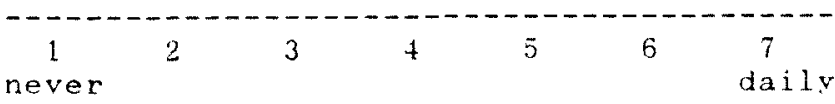

14. Assist her in financial matters like balancing her checkbook, cashing checks for her, computing taxes, etc.

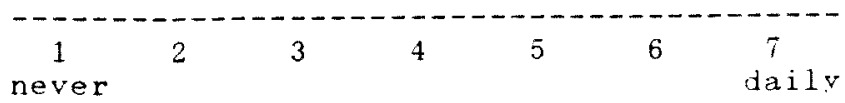

15. Fill out applications and forms for her, such as health or medical insurance, credit card, check cashing card, etc.

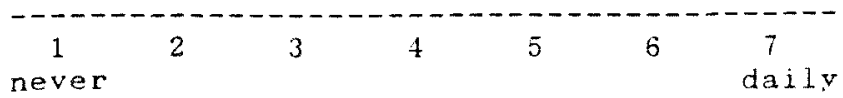

16. Have her in your home for a meal, visit, or other occasion

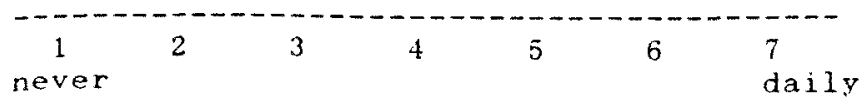


17. Take her out to dinner, movies, restaurants, plays, concerts, museums, etc.

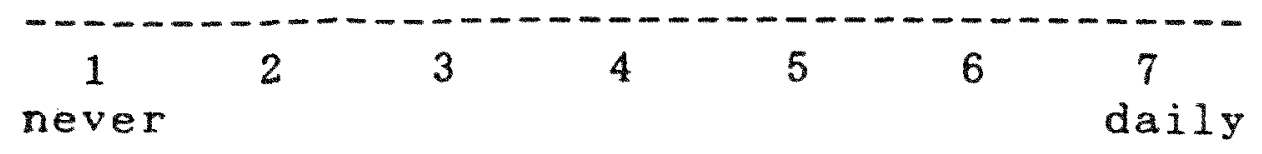

18. Take her to church or synagogue

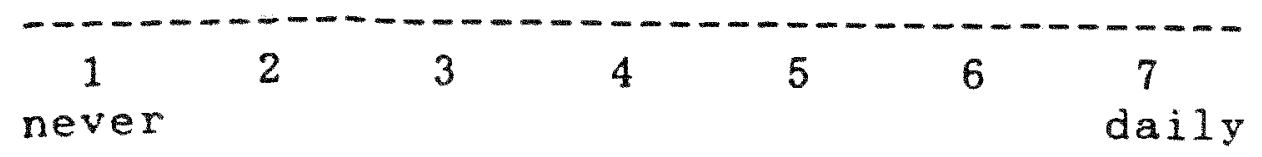


APPENDIX C 
INSTRUCTIONS: The following is a list of statements, which reflect how people sometimes feel when taking care of another person. After each statement, indicate how of ten you feel that way, never, rarely, sometimes, quite frequently, or nearly always. There are no right or wrong answers. Some statements may seem inappropriate for your situation, but please indicate your feeling on all items.

1. Do you feel that your mother asks for more help than she needs?
0. Never 1. Rarely
2. Sometimes
3. Quite Frequently
4. Nearly Always

2. Do you feel that because of the time you spend with your mother that you don't have enough time for yourself?
0. Never 1. Rarely
2. Sometimes
3. Quite Frequently
4. Nearly Always

3. Do you feel stressed between caring for your mother and trying to meet other responsibilities for your family or work?
0. Never 1. Rarely
2. Sometimes
3. Quite Frequently
4. Nearly Always

4. Do you feel embarrassed over your mother's behavior?
0. Never 1. Rarely
2. Sometimes
3. Quite Frequently
4. Nearly Always

5. Do you feel angry when you are around your mother?
0. Never 1. Rarely
2. Sometimes
3. Quite Frequently
4. Nearly Always

6. Do you feel that your mother currently affects your relationship with other family members or friends in a negative way?
0. Never 1. Rarely
2. Sometimes
3. Quite Frequently
4. Nearly Always

7. Are you afraid about what the future holds for your mother?
0. Never 1. Rarely
2. Sometimes
3. Quite Frequently
4. Nearly Always 
8. Do you feel your mother is dependent upon you?
0. Never 1. Rarely
2. Sometimes
3. Quite Frequently
4. Nearly Always

9. Do you feel strained when you are around your mother?
0. Never 1. Rarely
2. Sometimes
3. Quite Frequently
4. Nearly Always

10. Do you feel your health has suffered because of your involvement with your mother?
0. Never 1. Rarely
2. Sometimes
3. Quite Frequently
4. Nearly Always

11. Do you feel that you don't have as much privacy as you would like, because of your mother?
0. Never 1. Rarely
2. Sometimes
3. Quite Frequently
4. Nearly Always

12. Do you feel that your social life has suffered because you are caring for your mother?
0. Never 1. Rarely
2. Sometimes 3. Quite Frequently
4. Nearly Always

13. Do you feel uncomfortable about having friends over, because of your mother?
0. Never 1. Rarely
2. Sometimes
3. Quite Frequently
4. Nearly Always

14. Do you feel that your mother seems to expect you to take care of her, as if you were the only one she could depend on?
0. Never 1. Rarely
2. Sometimes
3. Quite Frequently
4. Nearly Always

15. Do you feel that you don't have enough money to care for your mother, in addition to the rest of your expenses?
0. Never 1. Rarely
2. Sometimes
3. Quite Frequently
4. Nearly Always

16. Do you feel that you will be unable to take care of your mother much longer?
0. Never 1. Rarely
2. Sometimes
3. Quite Frequently
4. Nearly Always 
17. Do you feel you have lost control of your life since your mother's illness?
0. Never 1. Rarely
2. Sometimes 3. Quite Frequently
4. Nearly Always

18. Do you wish you could just leave the care of your mother to someone else?
0. Never 1. Rarely
2. Sometimes 3. Quite Frequently
4. Nearly Always

19. Do you feel uncertain about what to do about your mother?
0. Never 1. Rarely
2. Sometimes
3. Quite Frequently
4. Nearly Always

20. Do you feel you should be doing more for your mother?
0. Never 1. Rarely
2. Sometimes
3. Quite Frequently
4. Nearly Always

21. Do you feel you could do a better job in caring for your mother?
0. Never 1. Rarely
2. Sometimes
3. Quite Frcquently
4. Nearly Always

22. Overall, how burdened do you feel in caring for your mother?
0 . Not at all
1. A little
2. Moderately
3. Quite a bit
4. Exiremely 
APPENDIX D 


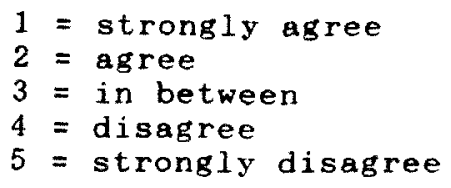

11. I have often felt tense from fighting, arguing, or disagreeing with my sister.

$\begin{array}{lllll}1 & 2 & 3 & 4 & 5\end{array}$

12. I often wish she understood me better.

\begin{tabular}{llll}
\hline & 2 & 3 & 4
\end{tabular}

13. She is the sort of person whom I myself would like to be.

$\begin{array}{lll}1 & 2 & 3\end{array}$

14. My sister and I are often in conflict.

$\begin{array}{llll}1 & 2 & 3 & 4\end{array}$

15. She often expresses approval of me or something I did.

\begin{tabular}{llll}
\hline 1 & 2 & 3 & 4
\end{tabular}

16. My sister often criticizes my relatives or friends.

$\begin{array}{llll}1 & 2 & 3 & 4\end{array}$

17. My sister and I often share our emotions, feelings, or problems with each other.

$\overline{1} \quad 2 \quad 3 \quad 4 \quad 5$

18. She doesn't listen when I try to give advice.

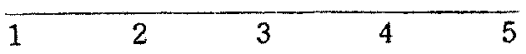

19. My sister and I are much closer than most.

\begin{tabular}{llll}
\hline 1 & 2 & 3 & 4
\end{tabular}

20. She and I have an excellent relationship.

\begin{tabular}{lllll}
\hline 1 & 2 & 3 & 4 & 5
\end{tabular}

